DOI: $10.22616 /$ REEP.2019.016

\title{
Reasoning the Implementation of Massive Open Online Courses in Higher Education Institutions
}

\author{
Danguole Rutkauskiene ${ }^{1}$ Ph.D.; Armantas Ostreika ${ }^{2}$ Ph.D.; Vytaute Monastyreckiene ${ }^{3}$ Mg. \\ Kaunas University of Technology, Lithuania \\ danguole.rutkauskiene@ktu.1t ${ }^{1}$; armantas.ostreika@ktu.1t²; vytaute.monastyreckiene@ktu.1t ${ }^{3}$
}

\begin{abstract}
First Massive Open Online Course (MOOC) was provided in 2013 by Kaunas University of Technology, since then few more institutions joined this initiative. The interest in MOOCs have been growing among Lithuanian higher education institutions, however the number of new MOOCs are not growing significantly. New initiatives are influenced by various factors, however it is important to examine the most relevant factors influencing decision to develop and provide MOOCs in order to develop measures for encouraging innovative learning methods in Lithuanian higher education. The aim of this article is to identify the main objectives that are important for higher education institutions (HEIs) when deciding to implement MOOCs in the institution. Authors of the article conducted the survey with representatives from 17 Lithuanian higher education (HE) institutions. The study shows that the most important objective of MOOCs implementation for Lithuanian HEIs is flexible learning opportunities. Results also represent that far Lithuanian HEIs do not acknowledge MOOCs as business opportunity, for them MOOCs are the innovation area and the opportunity to fulfil demands of wider range of learners.
\end{abstract}

Keywords: Massive Open Online Courses, distance education, Lithuanian HEIs, higher education.

\section{Introduction}

Massive Open Online Courses (MOOCs) have been there for a while. MOOCs have changed and evolved a lot, course providers experiment and innovate in this area up to now. MOOCs at the beginning were seen as the great marketing opportunity for higher education institutions even though flexibility and opening up education for everyone were also considered as the key factors of MOOCs. When MOOCs became more popular in the Europe, $2^{\text {nd }}$ wave began, they were considered to be an opportunity for lifelong learning by reducing skill gaps in the key industries. New $\left(3^{\text {rd }}\right)$ wave of MOOCs is emerging right now, higher education institutions are striving for recognition for the credits and creating new business models. MOOCs are still being provided for free, however some additional features such as certificates can be offered for a fee (Brown, 2018). Nevertheless, despite the different variations of MOOCs, they all have common elements (Patru, Balaji, 2016):

- massiveness - the courses are designed in the way that allow to provide courses for unlimited number of learners;

- openness - courses are free of charge;

- online - course are being provided through the internet.

Course. Learners are provided with well-balanced learning experience which include all necessary elements for knowledge and skill development in the certain area.

MOOCs are becoming more varied, because they are being developed as education opportunities for a wide range of people, from disadvantaged social groups to whom education is less accessible to employed professionals, who seek for vocational training or further development opportunities (Read, Barcena, Sedano, 2018). While MOOCs evolve and offer more features and possibilities for learners, in Lithuania it is possible to detect only few institutions that are providing MOOCs and are fond of openness and accessibility of education for everyone that they provide. First MOOC in Lithuania was offered in September, 2014 it was designed by lecturers of Kaunas University of Technology and gathered 2009 participants in total. The course was evaluated very positively, learning objects of this MOOC were anticipated to be interactive and engaging (Gudoniene, Rutkauskiene, 2015). Afterwards few other initiatives emerged, however in Lithuania MOOCs are not that widely spread as in other parts of Europe. Kaunas University of Technology still remains the leader in the provision of MOOCs in Lithuania. Other Lithuanian higher education institutions are interested in development of MOOCs, however it is not being taken to actions due to challenges of providing MOOCs with no experience, this creates lack of technical and pedagogical support for this kind of initiatives, preparedness of teachers to 
manage them also, the traditional learning attitude is very sturdy in Lithuanian educational system this makes it even more difficult to present new approach of learning. On the other hand, a lot of students express high levels of ICT competences and frequently use ICT as permanent measures for learning (Vronska, 2016). This means that if higher education institutions want to attract students and retain them, they have to adapt teaching methods to those that are used by their students, like various ICT measures. Therefore, the aim of this article is to identify the main objectives that are important for higher education institutions (HEIs) when deciding to implement MOOCs in the institution.

\section{Reasons of HEIs to implement MOOCs}

MOOCs are considered to bring significant amount of innovation to the education, even though before MOOCs other forms of online distance learning have already excited, MOOCs brought together features that were not combined before. The research published by O. Pilli, W. Admiraal, A. Salli investigates the factors that determine if MOOCs are worth to be invested or not by higher education institutions (Pilli, Admiraal, Salli, 2018). As one of the strengths of MOOCs, accessibility for large number of learners who have the access to the internet and life-long learning that MOOCs promote by providing more learning opportunities with less time constrains and adapting to various learning styles are being distinguished. Other strengths of MOOCs are - online learning communities where learners are able to connect with each other and share their experiences, backgrounds, experimentation opportunities that are provided by the ability to collect data from learners much more easily than in the traditional learning. MOOCs are also used for brand extension purposes by signalling innovation and providing courses to more diverse audience of learners (Pilli, Admiraal, Salli, 2018). P. Belleflamme and J. Jacqmin (2015) supplement this approach by distinguishing three additional benefits of MOOCs for learners. MOOCs enable retrieval-based learning, because they use tests that are automatically graded, provide instant feedback and ability to asses one's knowledge and most importantly this constant testing helps improving long term memory of the students. This type of learning provides more learner-centred environment, because it is easier to provide more adapted content and assignments according to the knowledge level of each of the learner and most importantly, to allow him to study in his own pace. Lastly, MOOCs provide a wide range of data about the learners for the course provider, he can gather data by changing learning conditions, mixing groups and this helps to make conclusions about the improvement of MOOCs platforms.

As every form of education, MOOCs have their weaknesses that also should be taken into consideration by higher education institutions. Weaknesses such as high dropout rate that are due to the necessary learners' high self-motivation and responsibility for learning process, infrastructure of MOOCs can be expensive if institution do not own a platform for MOOC and has no experience in designing them. Pedagogical aspects determine that MOOCs yet are not able to develop high level of academic learning. Also, MOOCs are more orientated towards providing courses, but not to the learning process itself. Also, the assessment still can be too superficial, it faces the problem of plagiarism that interfere with recognition of MOOC credits (Bates, 2015). MOOCs are striving to be open and massive that brings unique challenges in the learning process. Since educators sometimes rely on the same design methodologies as for their F2F or online courses that lack massiveness or openness while designing MOOCs, they do not meet the needs of very large population of learners with different learning experiences and backgrounds, different languages and cultures (Bali, 2014).

After considering the pros and cons of MOOCs, higher education institutions have to decide which strategies for delivering them are the most relevant for their institution. It should be considered if institution will be able to support MOOC by themselves or choose to provide it on external platform. The development strategies of new teaching approaches implementation in educational community should be anticipated. Novelties sometimes can be met as the threats, because they require time, technological investments and development of new skills. Further, overall university strategy has to be adapted according to the new teaching approaches and research, training opportunities should be encouraged (Belleflamme, Jacqmin, 2015).

Lithuanian higher education institutions are guided by national strategy. Progress report "Lietuva 2030" is one of the most important documents of education objectives in Lithuania (Lithuania's progress strategy..., 2018). It defines the important factors of education that are: the quality of curriculum and how it is provided, learning tools and environment, teaching staff - their demographic characteristics, 
education, inclusion - the availability of education, adaptability to different learning needs, education culture - uniform direction of development, independency of education institutions, monitoring and analysis of the activity. Lithuanian HEIs are constantly pushed to review their standards, update learning environment. Whereas in Lithuania the number of new students is decreasing every year and the financing of HEIs directly depends on the quantity of students, therefore they have to adapt their strategy and find new sources for income, search for new learners consequently, distance implementation of education becomes more accurate.

\section{Methodology}

The study is based on previously conducted reports on MOOCs in European level in the year 2014 (Jansen and Schuwer, 2015) and 2015 (Jansen, Goes-Daniels, 2016). Authors of the article used the questions from previously mentioned reports and designed a semi-closed questionnaire suitable for Lithuanian sample. 17 Lithuanian higher education institutions were surveyed. Each of the responding institutions were asked to choose one representative, an expert who is working in the institution and would be able to represent it and answer the given questions. Representatives were chosen according to their acquaintance to institutions' policy, MOOCs design and delivery. This survey was performed three times with the same respondents in 2015, 2016 and 2018. In this article the results form 2018 are compared to the results from 2016 and 2015.

\section{Results and Discussion}

The main goal of the survey was to examine the main objectives that are important for Lithuanian HEIs when deciding to implement MOOCs in the institution. Figure 1 represents current situation of MOOCs offerings in Lithuania.

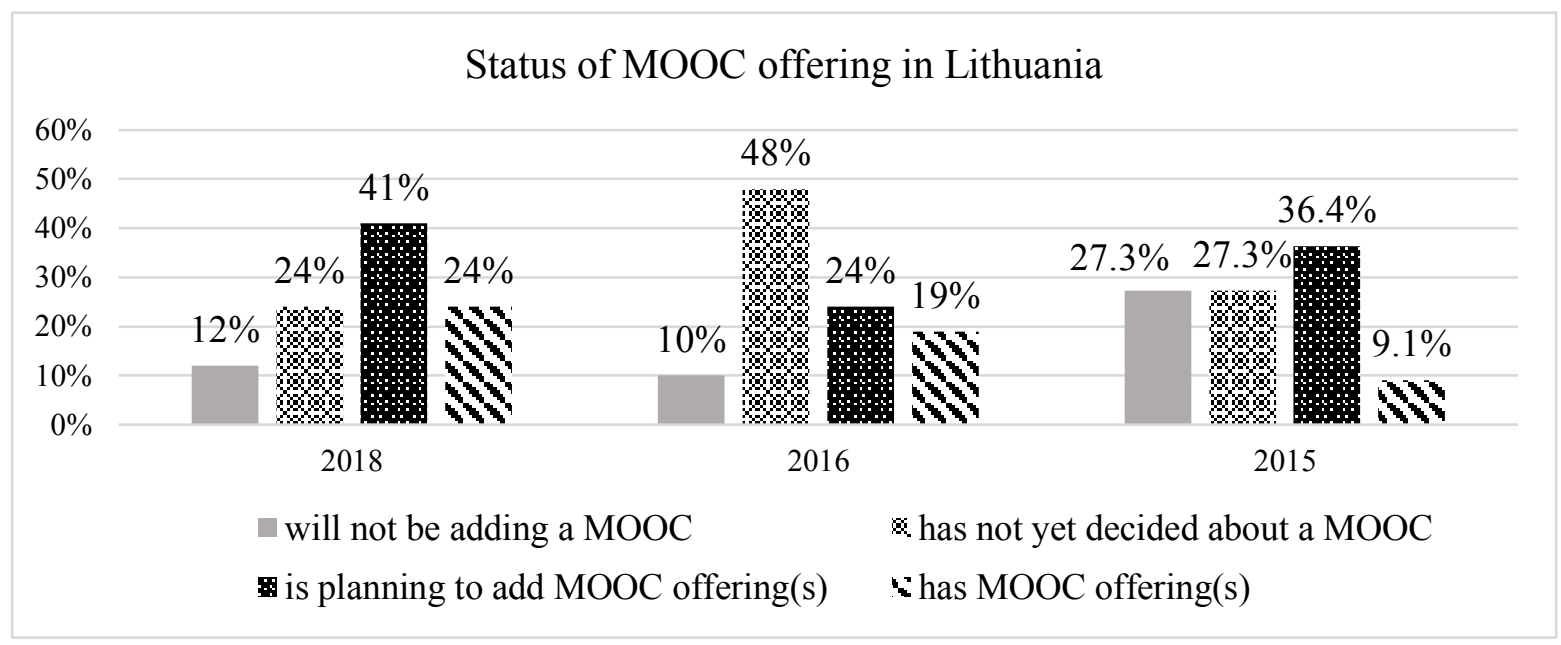

Figure 1. Alteration of Lithuanian HE institutions MOOCs offering profile.

Recent results indicate that the percentage of institutions offering MOOCs have increased from $9,1 \%$ (in 2015 ) to $10 \%$ (in 2016) and have reached $24 \%$ in 2018. Intention to add MOOC offerings to an educational process considerably varied since 2015 years from $36,4 \%$ dropped to $24 \%$ in 2016 and recently the percentage of institutions planning to add MOOCs to their curricula have increased to $41 \%$ (in 2018). In $201824 \%$ of respondents were uncertain if they are going to add MOOCs to their offerings and $12 \%$ expressed that they are not going to add MOOCs in the future. Survey of the year 2018 displayed that currently 2 institutions have offered 5 MOOCs since 2012 until now, 1 institution offered -2 MOOCs and 2 other institutions have offered 1 MOOC. In total, number of offered MOOCs in Lithuania have increased from 2016 year. This shows that institutions are creating new courses and also are willing to add them to the study programs. One institution $(10 \%)$, which already use MOOCs is collaborating on a MOOC platform in its region/country. Two other institutions (20\%) have developed their own dedicated institutional MOOC platform and remaining seven institutions (70\%) that already have adapted MOOCs are using existing software for their institutional MOOC platform (e.g., Moodle, OpenedX, etc).

Figure 2 represents the answers to the question how well MOOCs meet institutional objectives. The majority (41\%) of respondents replied that it is too early to tell (in 2018), however this answer remained 
the most popular since 2015 (45,5\%). It is worth mentioning that results in 2018, 2016 and 2015 remained similar, the answers are consistent. $41 \%$ replied that MOOCs meet some or all $/$ most of the institution's objectives and 18\% agreed that MOOCs meet very few institution's goals.

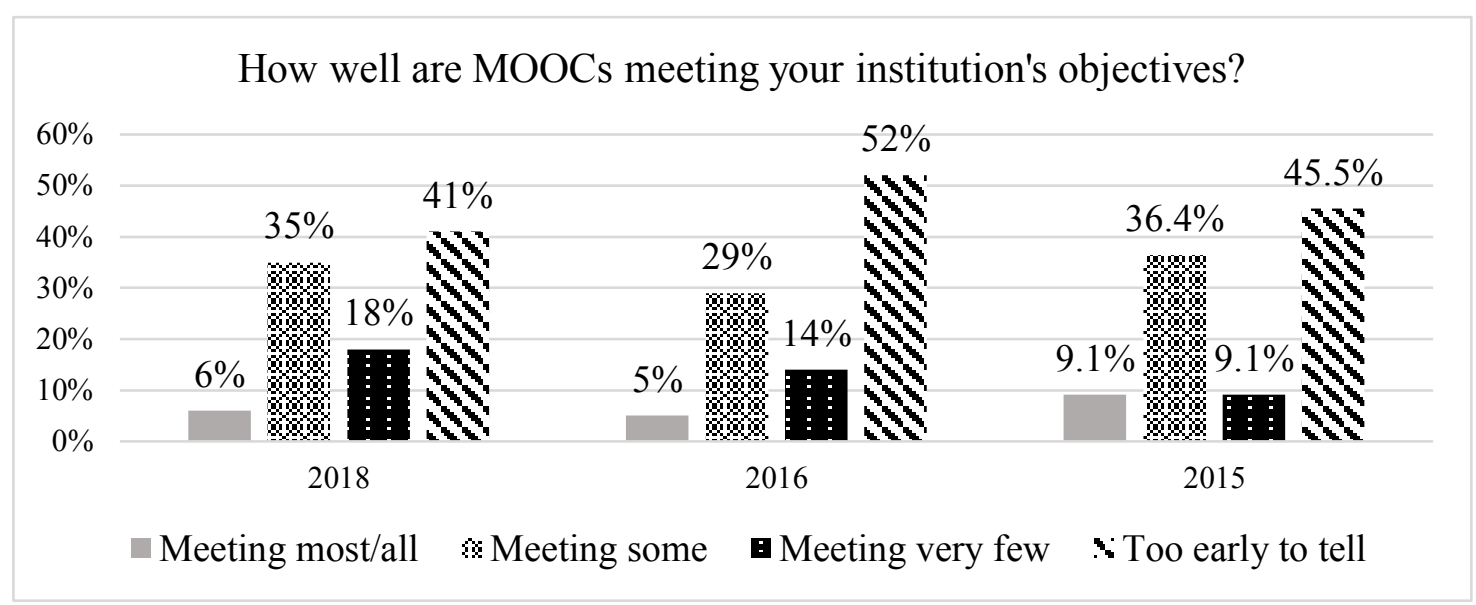

Figure 2. MOOCs compliance with institution's goals.

Primary objectives of MOOCs of Lithuanian HEIs offering were mentioned as flexible learning opportunities (29\%), innovative pedagogy (24\%), increased institutions visibility (18\%) and reach of new students (18\%) (see figure 3). Compared to the previous studies it is obvious that results are corresponding to 2016 where the most important primary goals were also mentioned as flexible learning opportunities (33\%), increase institution's visibility (24\%), innovative pedagogy (24\%) and reaching new students (14\%). More noticeable distinction in opinion is in the 2015 there the most important primary objective was named as the increase in institution visibility $(73 \%)$.

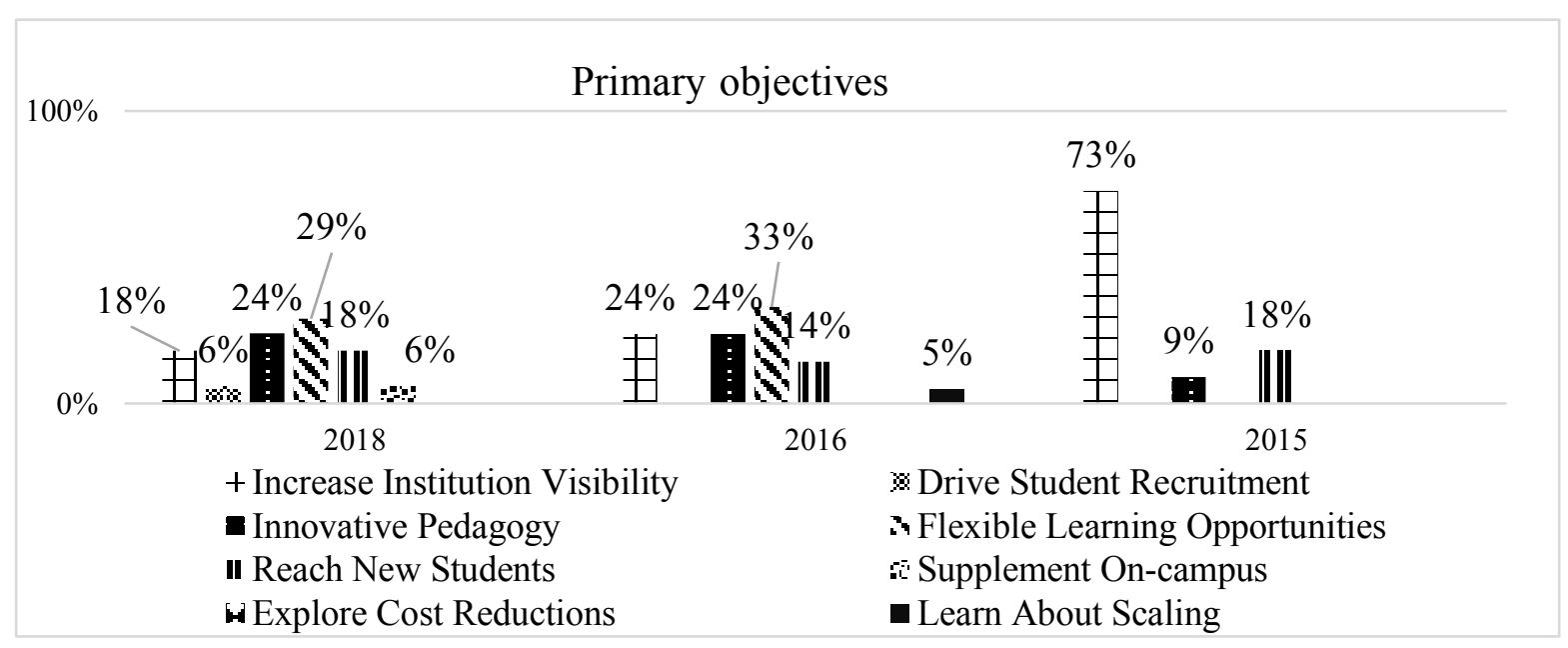

Figure 3. Primary objectives of MOOCs.

Respondents were asked to evaluate the relevance of four clusters: responding to the demands of learners, MOOCs as innovation area, using MOOCs for reputation or visibility and using MOOCs for financial reasons. On the contrary to the question above where respondents were asked to select the most important objectives, respondents indicated the relevance of each cluster.

Participants assessed using MOOCs for reputation / visibility reasons as the most important cluster. In total $88 \%$ of respondents consider it to be relevant or highly relevant for their institutions. MOOCs as innovation area (29\% - highly relevant, $59 \%$ - relevant) and responding to demands of learners (highly relevant $-41 \%$, relevant $-24 \%$ ) were also evaluated as very important clusters (see figure 4 ). Using MOOCs for financial reasons was evaluated as not very important cluster for HEIs this might be explained by relatively low learners' engagement and popularity of MOOCs in Lithuania. 


\section{Relevance of MOOCs objectives}

$\begin{array}{clll} & 6 \% & 29 \% & 24 \%\end{array}$

$$
\begin{array}{lllllll}
0 \% & 20 \% & 40 \% & 60 \% & 80 \% & 100 \% & 120 \%
\end{array}
$$

Not at all relevant for my institution

E Neither irrelevant or relevant

s Highly relevant for my institution
III Somewhat relevant for my institution

$\because$ Relevant for my institution

Figure 4. Relevance of MOOCs objectives 2018.

Four following figures represent the comparison between four clusters (innovation area, reputation / visibility, demands of learners and societies, financial reasons) and surveys of 2018, 2016 and 2015. Figure 5 shows that there was a significant difference in the importance of the innovation area of MOOCs in HEIs. The increase of the importance was detected from 2015 (highly relevant and relevant $-64 \%$ ) and 2016 (highly relevant and relevant $-76 \%$ ) to 2018 highly relevant and relevant $-88 \%$ ).

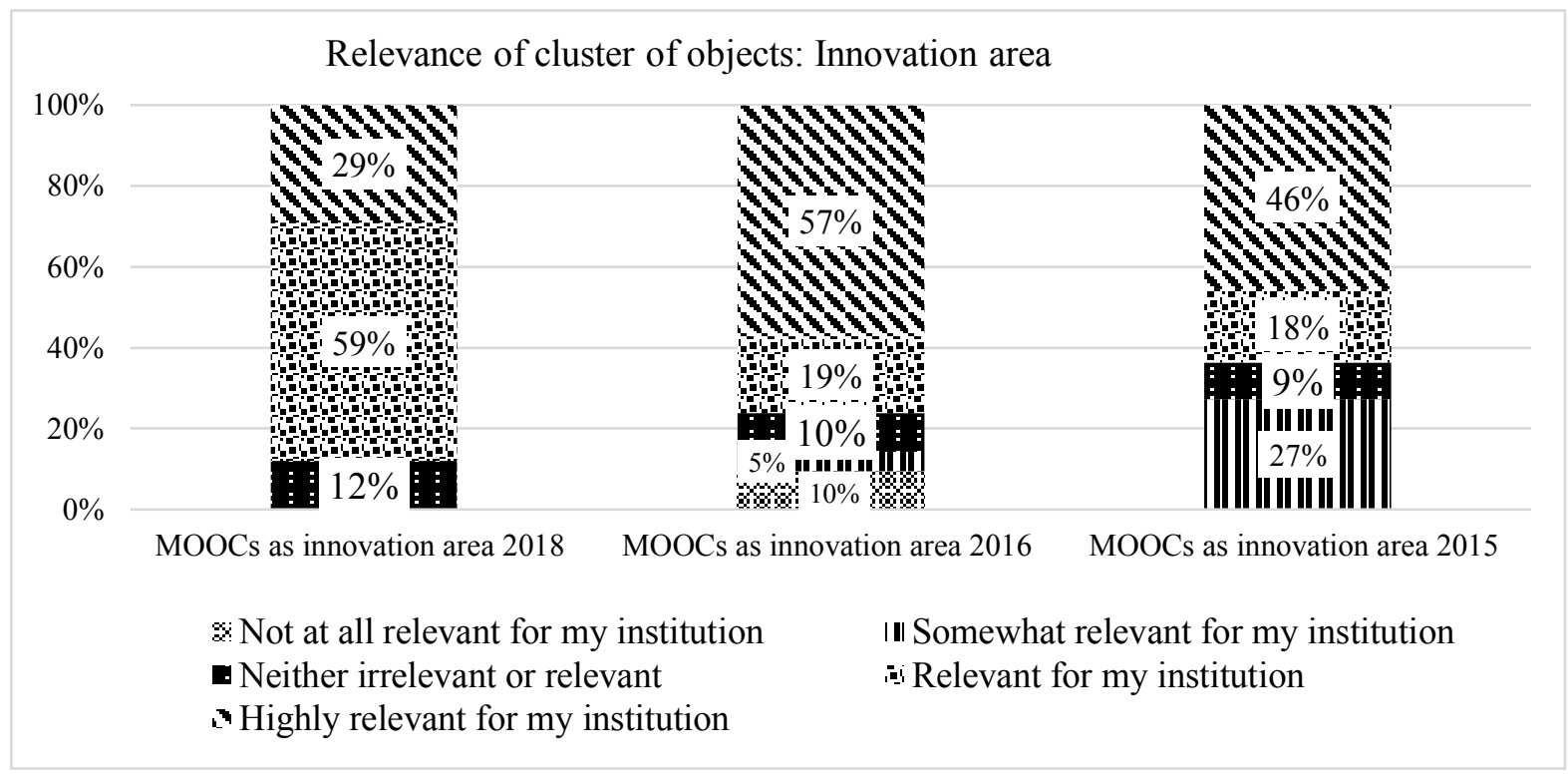

Figure 5. Relevance of MOOCs objectives: Innovation area.

When comparing results between responses to reputation and visibility aspect of MOOCs. In $201582 \%$ of HEIs perceived that reputation / visibility cluster is highly relevant and relevant in comparison to $81 \%$ in 2016 and $76 \%$ in 2018 . The relevance of MOOCs reputation and visibility is decreasing (see Figure 6). 


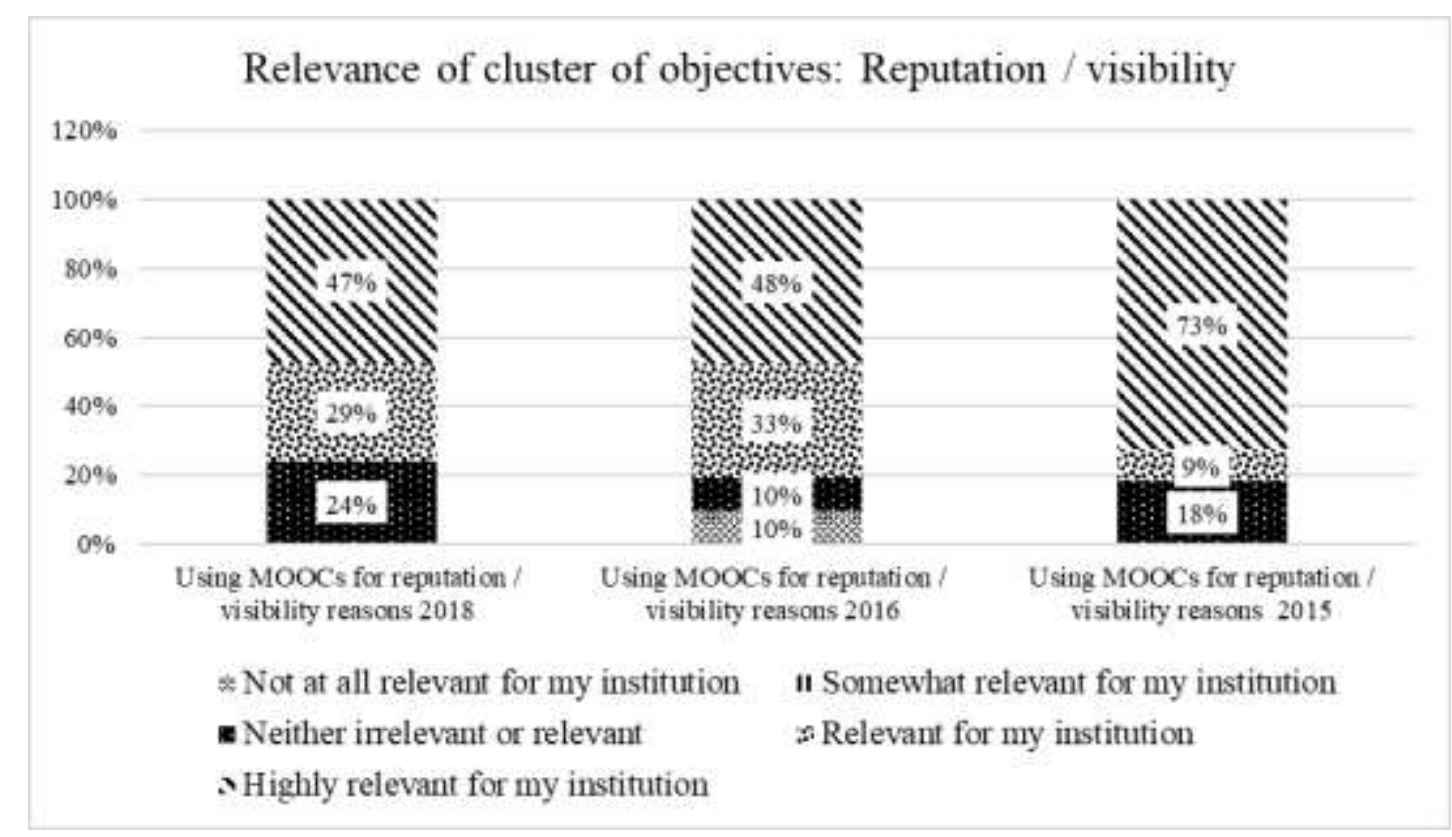

Figure 6. Relevance of MOOCs objectives: Reputation / visibility.

Figure 7 shows that the institutional relevance in responding to demands of learners and societies remained approximately at the same rate from 2016 (highly relevant $-43 \%$, relevant $-24 \%$ ) to 2018 (highly relevant $-41 \%$, relevant $-24 \%$ ). The survey shows that MOOCs are considered to be a great tool to fulfil learners' demands at HEIs because of the augmentation in positive responses from 2015 (highly relevant - 27\%).

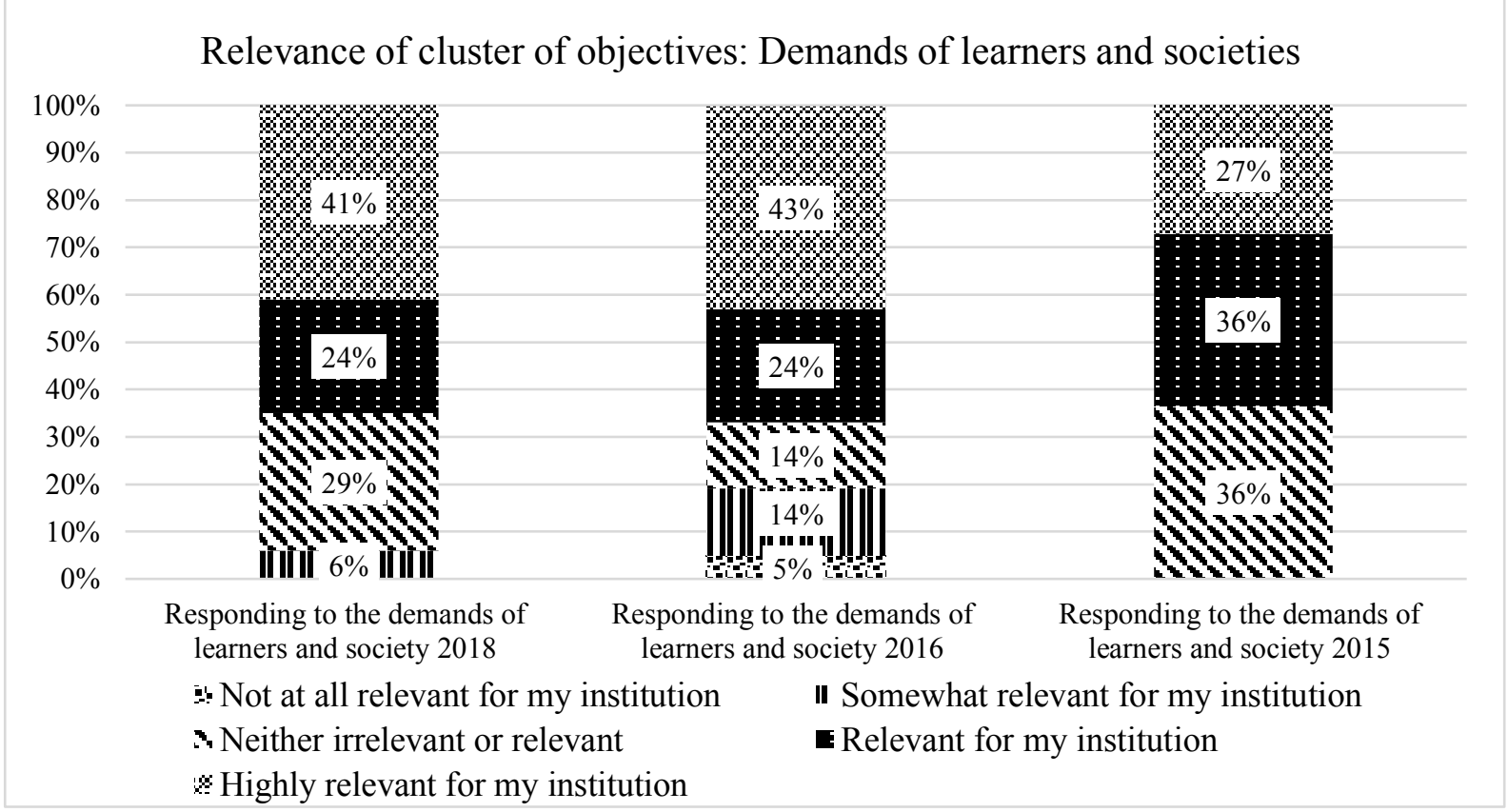

Figure 7. Relevance of MOOCs objectives: Demands of learners and societies.

Figure 8 shows the relevance of financial aspect of MOOCs to HEIs. Financial reasons are seen as not very important reasons to choose provide MOOCs. The differentiation in opinions is not very apparent, however it is possible to notice the decrease of financial cluster importance: 2015 (highly relevant and relevant -36\%), 2016 (highly relevant and relevant - 29\%), 2018 (highly relevant and relevant - 24\%). 


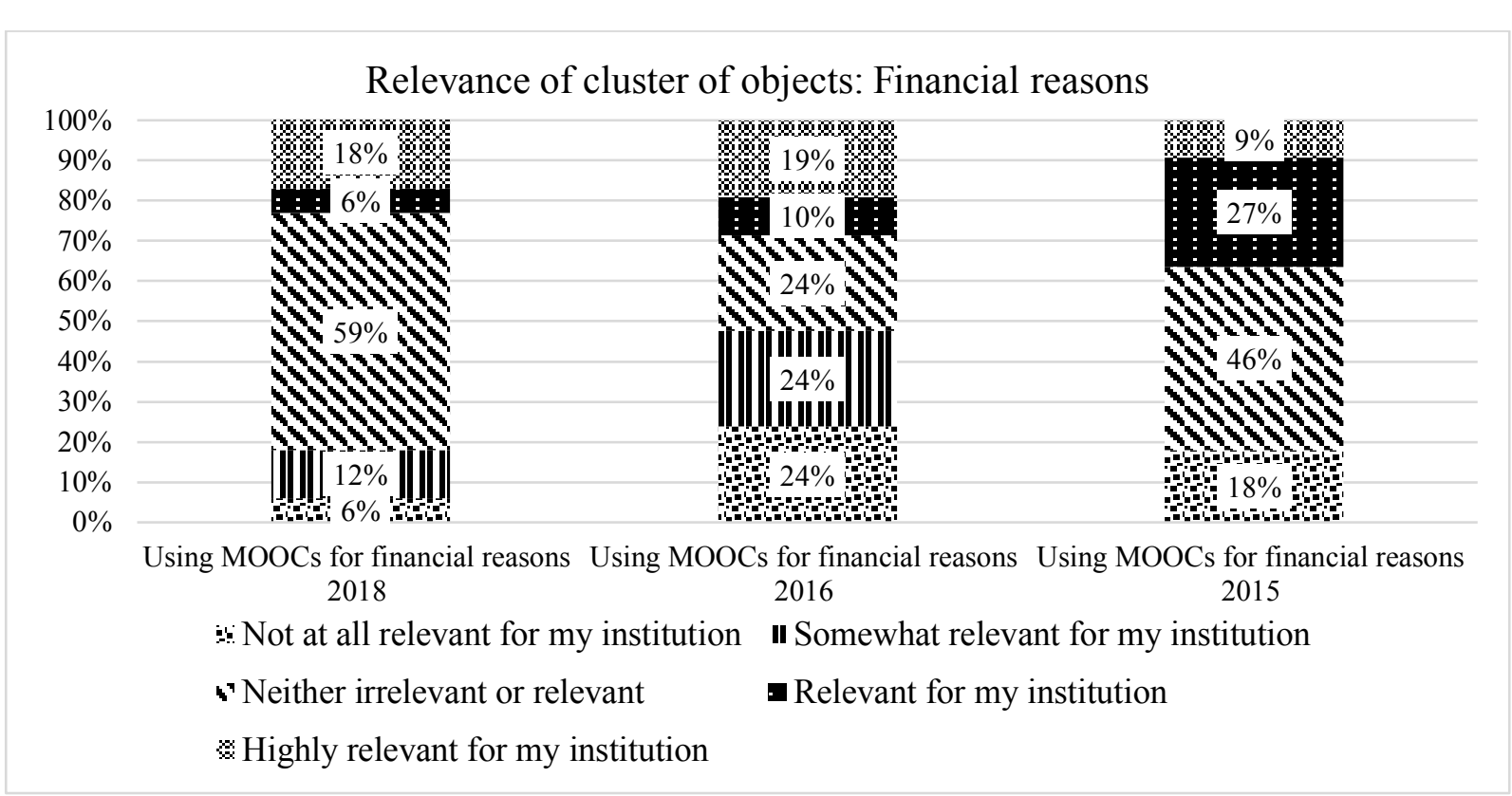

Figure 8. Relevance of MOOCs objectives: Financial reasons.

MOOCs in HEIs are also acting as the means to "rise teachers' competencies to use innovative learning technologies" or for "updating curricula for general education, development teachers' competencies". Even though of HEIs representatives are aware of MOOCs advantages, the uptake of MOOCs is still not very considerable. Respondents adverted the problem of not enough funding ("lack of funding") as a most important cause which prevents mature uptake of MOOCs. Also, it was mentioned that absence of "Recognition" is a problem same as widely established traditional education and slow assimilation of innovations: "...strong classical traditions of learning", "educational system", "Teachers do not believe in MOOC quality...", "...conservatism of HE". Respondents also were asked that in their opinion, would boost the use/uptake of MOOCs in their region. The most common answer was that it is necessary to create funding system for MOOCs: "Special funding programmes", "special funding for creating and delivery of MOOCs". Likewise, it is important to notice that in order to uptake MOOCs better it is necessary to resolve its" "recognition", "legalization..." problem.

\section{Conclusion}

Higher Education Institutions decides to deliver MOOCs due to composite reasons. Literature review showed that HEIs mostly implement MOOCs for prestige and visibility. Also, it indicates the level of innovation in the Higher Education Institutions as MOOCs require new technological and methodological solutions while implementing and delivering them to learners. The results of the research supplement the Literature review by showing that MOOCs increase visibility, innovations in pedagogy and flexible learning opportunities for Higher Education Institutions. Moreover, HEIs that decide to deliver MOOCs not for financial beneficiary, but mostly for demands of learners and society and implementation and demonstration of new innovations in educational technologies and methodology. These results indicate that MOOCs mostly are used for increasing reputation which helps HEIs to stay competitive in the market as well as suggest more services for wider society.

\section{Bibliography}

1. Bali M. (2014). MOOC pedagogy: gleaning good practice from existing MOOCs. Journal of Online Learning and Teaching, 10(1), 44-55. Retrieved from https://pdfs.semanticscholar.org/5e91/05f38d1d042f0a15cd1378af4427f685b869.pdf

2. Bates T. (2015). Teaching in digital age: Guidelines for designing teaching and learning. Retrieved from_http://opentextbc.ca/teachinginadigitalage/

3. Belleflamme P., Jacqmin J. (2015). An economic appraisal of MOOC platforms: business models and impacts on higher education. CESifo Economic Studies, 62(1), 148-169.

4. Brown M. (2018). Why Invest in MOOCs? Strategic Institutional Drivers. In D. Jansen, L. Konings (Eds.), The 2018 OpenupEd Trend Report on MOOCs, 6-9. Maastricht, NL: EADTU. 


\section{Retrieved from}

https://www.openuped.eu/images/Publications/The_2018_OpenupEd_trend_report_on_MOOCs.pdf

5. Gudoniene D., Rutkauskiene D. (2015). Pirmieji masiniai atviri internetiniai kursai Lietuvoje: mokymosi objektų reikšmė mokymosi kokybei (The first massive open online courses in Lithuania: the importance of learning objects for learning quality). Informacijos mokslai, 71(71), 115-123. (in Lithuanian)

6. Jansen D., Goes-Daniels M. (2015). Comparing Institutional MOOC strategies. Retrieved from http://eadtu.eu/images/publicaties/Comparing_Institutional_MOOC_strategies.pdf

7. Jansen D., Schuwer R. (2015). Institutional MOOC strategies in Europe. Status Report Based on a Mapping Survey Conducted in October-December 2014. Mimeo. Retrieved from https://www.surfspace.nl/media/bijlagen/artikel-1763-22974efd1d43f52aa98e0ba04f14c9f3.pdf

8. Lithuania's progress strategy "Lithuania 2030". (2018). Lithuania: State progress council. Retrieved from https://www.lietuva2030.1t/en/download/2351e1f89324e88e4ccf7c72b74a162a2dec6a69e042908431/1

9. Patru M., Balaji V. (Eds.). (2016). Making sense of MOOCs: A Guide for policy-makers in developing countries. Retrieved from

http://dspace.col.org/bitstream/handle/11599/2356/2016_Guide-on-MOOCs-for-Policy-Makers- inDeveloping-Countries.pdf?sequence $=4 \&$ is Allowed $=\mathrm{y}$

10. Pilli O., Admiraal W., Salli A. (2018). MOOCs: Innovation or Stagnation? Turkish Online Journal of Distance Education, 19(3), 169-181. Retrieved from http://dergipark.gov.tr/download/article-file/508838

11. Read T., Barcena E., Sedano B. (2018). Current Trends in MOOC Research and Applications. In D. Jansen, L. Konings (Eds.), The 2018 OpenupEd Trend Report on MOOCs. Maastricht, NL: EADTU, 10-13. Retrieved from https://www.openuped.eu/images/Publications/The_2018_OpenupEd_trend_report_on_MOOCs.pdf

12. Vronska N. (2016). ICT Competences as a Necessary Part of Professional Qualities at the Latvia University of Agriculture. In V. Dislere (Ed.), The Proceedings of the International Scientific Conference Rural Environment. Education. Personality (REEP), 9. Jelgava: LLU TF, 122127. Retrieved from http://llufb.llu.lv/conference/REEP/2016/Latvia-Univ-Agricult-REEP2016proceed2255-808X.pdf 